\title{
BLOOD CELL COUNTS AND BLOOD CELL RATIOS AS NON-SPECIFIC MAJOR DEPRESSIVE DISORDER BIOMARKERS
}

\section{Krivosova $\mathbf{M}^{1}$, Kusnir $\mathrm{P}^{1}$, Kertys $\mathbf{M}^{1,2}$, Mestanik $\mathbf{M}^{2,3}$, Tonhajzerova $\mathrm{I}^{3,2}$, Hrtanek $\mathrm{I}^{4}$, Ondrejka $\mathrm{I}^{4}$, Mokry J.,}

\author{
${ }^{1}$ Department of Pharmacology, Jessenius Faculty of Medicine in Martin, \\ Comenius University in Bratislava, ${ }^{2}$ Biomedical Center Martin, Jessenius Faculty \\ of Medicine in Martin, Comenius University in Bratislava, ${ }^{3}$ Department of Physiology, \\ Jessenius Faculty of Medicine in Martin, Comenius University in Bratislava, \\ ${ }^{4}$ Clinic of Psychiatry, Jessenius Faculty of Medicine in Martin, Comenius University \\ in Bratislava and Martin University Hospital, Martin, Slovak Republic
}

\begin{abstract}
A b s tract
Introduction: With an increasing prevalence of major depressive disorder (MDD) in population there is a particular interest in finding a suitable biomarker for diagnosis and prognosis of the disease. Many studies have shown that MDD is linked to a systemic inflammatory process, so blood elements counts and ratios have been suggested to be promising indicators in the management and effectiveness of the disease therapy. The aim of this retrospective study was to compare absolute and relative white blood cells counts and to search for any changes in their ratios before and after the therapy of the patients.

Methods: Our study included 36 patients who were admitted to hospital with either a new diagnosis or a recurrent episode of MDD and who were treated by a standard protocol. The peripheral blood samples were collected both at admission and at hospital discharge. Absolute white blood cell count and counts of neutrophils, lymphocytes, monocytes, platelets, as well as mean platelet volume, red blood cell distribution width, neutrophil/lymphocyte ratio, platelet/lymphocyte ratio, and monocyte/lymphocyte ratio before and after hospitalization (14-29 days) were evaluated and compared. The test of normality was performed and, accordingly, single t-test or MannWhitney U-test was used for data analysis.

Results: There were no significant differences between any blood cell ratios in blood samples before and after stay in hospital and appropriate treatment. Monocyte count was significantly higher in MDD patients after hospital discharge $(\mathrm{p}=0.007)$, there was a significantly higher difference in discharged patients suffering from MDD recurrent episode (F.33) compared to newly diagnosed MDD ( $F .32)$ patients $(p=0.010)$. In patients treated with venlafaxine $(\mathrm{N}=23)$ there was a significant increase in monocyte/lymphocyte ratio observed at the end of hospitalization $(\mathrm{p}=0.018)$.

Conclusions: The pharmacotherapy and additive treatment of the patients suffering from MDD led only to mild changes in blood cells counts. As our study included only a small number of patients, and blood cell parameters and ratios were compared after a relatively short duration of treatment, further and more detailed research is needed for final conclusions.
\end{abstract}

Key words: major depressive disorder (MDD), blood cell counts, blood cell ratios, biomarkers, antidepressants, venlafaxine

\section{INTRODUCTION}

Major Depressive Disorder (MDD) is a mental illness with a versatile aetiology leading to disability and impaired quality of life. There are 322 million people suffering from depressive disorders in the world (4.4\% of global population). The prevalence in Slovakia is estimated to be $5.1 \%$ of population in all age groups (1). Moreover, depression is predicted to

\section{Corresponding author:}

PharmDr. Michaela Krivošová, Department of Pharmacology, Jessenius Faculty of Medicine in Martin, Comenius University in Bratislava, Malá Hora 4C, 03601 Martin, Slovak Republic;

phone: 043/2633603, email: krivosova6@uniba.sk 
be the second biggest contributor to the global burden of disease by 2020 (calculated as DALYs - Disability Adjusted Life Years) (2). Although different approaches to treat the condition were investigated, there are still about $40 \%$ of people with no response to a first choice administration, patients with relapse or clinically significant residual symptoms and factors causing poor curative efficacy are many times unknown $(3,4)$. Many studies have shown that MDD is linked to a systemic inflammatory process $(5,6,7,8,9)$, therefore, inflammation biomarkers, e.g. C-reactive protein (CRP), interleukin (IL)-1, IL-6, tumor necrosis factor (TNF)- $\alpha$, were suggested to be suitable diagnostic and prognostic tools (10, $11,12)$. The immune system has impact on depression and vice versa - the inflammatory response may be generated in depressive disorders (10).

In recent years biomarker search has focused also on parameters obtained from a basic hemogram test such as blood cell counts and blood cell ratio counts $(13,14,15)$. They are easily and inexpensively measured and may inform us about the blood contents (16). In 2018 Mazza et al. published a meta-analysis about neutrophil/lymphocyte (NLR) and platelet/lymphocyte ratios (PLR) in mood disorders. In total 11 studies were included, from which just 4 were related to MDD. Patients with MDD had higher NLR as compared with healthy controls (17). Another study compared the severity of depression and cardiovascular risk factors with NLR value and found a positive correlation (18). As far as we know there has not been published any article about monocyte/lymphocyte ratio (MLR) in MDD yet. Demircan et al. (15) and Cai et al. (3) included in their research also mean platelet volume (MPV) and red blood cell distribution width (RDW) as possible indicators of immune-inflammation in MDD. Platelets are a non-specific first line inflammatory marker regulating parameters like endothelial permeability and recruitment and effector functions of neutrophils and macrophages. Volume of thrombocytes is inversely proportional to their amount $(17,19,20)$. RDW measures the degree of variation in red blood cell size or volume. An increased RDW is expected in inflammatory and infectious conditions as a result of releasing premature reticulocytes into the circulation. The higher RDW levels are suggested to be in chronic inflammatory pathologies compared to acute conditions $(15,17)$. Cai et al. found that both MPV and RDW as well as NLR levels are higher in MDD patients compared with healthy subjects and Demircan et al. recorded the decrease of all of them after 3-month antidepressant treatment in patients with the diagnosis of MDD. However, MPV parameter is dependent on various factors, including time of analysis after blood collection, anticoagulant used, or method of analysis. Thus, the reproducibility is highly dependent on standardized laboratory techniques (19). In another study NLR significantly increased after 12 weeks of appropriate depression pharmacotherapy in female subjects. Moreover, the results indicated that increased NLR was associated with reduced both depressive symptoms and risk of suicide (21).

The aim of this study was to evaluate basic blood cell counts - white blood cell count (WBC) as well as differential - neutrophil, lymphocyte, and monocyte counts; platelet count plus mean platelet volume (MPV) and red blood cell distribution width (RDW); and blood cell ratios according to literature background - NLR, PLR, and MLR before and after hospitalization and antidepressant treatment.

\section{METHODS}

Totally 36 adult patients (21 females and 15 males aged 18-75) with the diagnosis F32 (Major Depressive Disorder, single episode) or F33 (Major Depressive Disorder, recurrent episode) according to both ICD-10-CM codes and DMS-5 (American Psychiatric Association, 2013) admitted to the Clinic of Psychiatry of Martin University Hospital in Slovakia between July 2017 and June 2018 were included in the study. None of the patients included in the study suffered from chronic inflammatory disease, infection, or hemato-oncological disease.

Two blood samples - at admission (the second day) and at discharge from hospital (the last day) were taken. The period spent in the hospital was between 14 and 29 days (21 
Table 1: Comparison of blood cell parameters and ratios before and after hospitalization (mean \pm SD)

\begin{tabular}{|l|c|c|c|}
\hline \multicolumn{4}{|c|}{ All MDD patients (N=36) } \\
\hline Parameter & At hospital admission & At hospital discharge & $P$ value \\
\hline WBC count $\left(10^{9} / \mathrm{L}\right)$ & $7.279 \pm 2.970$ & $7.475 \pm 2.321$ & 0.362 \\
\hline Neutrophil count $\left(10^{9} / \mathrm{L}\right)$ & $4.148 \pm 1.915$ & $4.211 \pm 1.629$ & 0.789 \\
\hline Lymphocyte count $\left(10^{9} / \mathrm{L}\right)$ & $2.351 \pm 0.965$ & $2.413 \pm 0.858$ & 0.219 \\
\hline Monocyte count $\left(10^{9} / \mathrm{L}\right)$ & $0.491 \pm 0.250$ & $0.559 \pm 0.237$ & $0.007^{*}$ \\
\hline Platelet count $\left(10^{9} / \mathrm{L}\right)$ & $273.083 \pm 83.230$ & $269.722 \pm 105.217$ & 0.818 \\
\hline Mean platelet volume (FL) & $8.728 \pm 0.985$ & $8.767 \pm 1.006$ & 0.572 \\
\hline Red blood cell distribution width (\%) & $12.533 \pm 0.794$ & $12.572 \pm 0.812$ & 0.288 \\
\hline Neutrophil/lymphocyte ratio & $1.885 \pm 0.813$ & $1.880 \pm 0.772$ & 0.637 \\
\hline Platelet/lymphocyte ratio & $126.806 \pm 50.160$ & $118.084 \pm 47.505$ & 0.239 \\
\hline Monocyte/lymphocyte ratio & $0.215 \pm 0.074$ & $0.242 \pm 0.090$ & 0.053 \\
\hline
\end{tabular}

Table 2: Comparison of blood cell parameters and ratios before and after hospitalization in patients with venlafaxine treatment (mean $\pm \mathrm{SD}$ ).

\section{Patients with venlafaxine treatment $(\mathrm{N}=23)$}

\begin{tabular}{|l|c|c|c|}
\hline Parameter & At hospital admission & At hospital discharge & $P$ value \\
\hline WBC count $\left(10^{9} / \mathrm{L}\right)$ & $7.025 \pm 2.399$ & $7.321 \pm 2.615$ & 0.456 \\
\hline Neutrophil count $\left(10^{9} / \mathrm{L}\right)$ & $3.919 \pm 1.488$ & $4.087 \pm 1.800$ & 0.648 \\
\hline Lymphocyte count $\left(10^{9} / \mathrm{L}\right)$ & $2.376 \pm 0.881$ & $2.424 \pm 0.998$ & 0.648 \\
\hline Monocyte count $\left(10^{9} / \mathrm{L}\right)$ & $0.467 \pm 0.226$ & $0.553 \pm 0.271$ & $0.008^{*}$ \\
\hline Platelet count $\left(10^{9} / \mathrm{L}\right)$ & $288.652 \pm 85.747$ & $267.826 \pm 118.310$ & 0.331 \\
\hline Mean platelet volume (FL) & $8.813 \pm 1.171$ & $8.909 \pm 1.174$ & 0.346 \\
\hline Red blood cell distribution width $(\%)$ & $12.461 \pm 0.657$ & $12.496 \pm 0.694$ & 0.484 \\
\hline Neutrophil/lymphocyte ratio & $1.739 \pm 0.693$ & $1.866 \pm 0.876$ & 0.915 \\
\hline Platelet/lymphocyte ratio & $130.694 \pm 51.576$ & $117.378 \pm 50.838$ & 0.114 \\
\hline Monocyte/lymphocyte ratio & $0.200 \pm 0.072$ & $0.240 \pm 0.095$ & $0.011^{*}$ \\
\hline
\end{tabular}




\begin{tabular}{|c|c|c|c|c|c|c|c|c|c|c|c|c|}
\hline & & 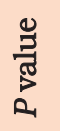 & $\begin{array}{l}0 \\
\stackrel{0}{-} \\
\stackrel{0}{0}\end{array}$ & $\begin{array}{l}\vec{\emptyset} \\
\infty \\
0\end{array}$ & $\begin{array}{l}\text { ஸै } \\
\stackrel{0}{0}\end{array}$ & $\begin{array}{l}\overbrace{0}^{*} \\
0 \\
0 \\
0\end{array}$ & $\begin{array}{l}\overrightarrow{6} \\
\text { ?. }\end{array}$ & 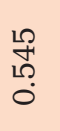 & $\begin{array}{l}\text { Lि } \\
\text { மீ } \\
\text { மீ. }\end{array}$ & $\begin{array}{l}N \\
\infty \\
\infty \\
0 \\
0\end{array}$ & $\begin{array}{l}\hat{\delta} \\
\text { లి } \\
0\end{array}$ & $\begin{array}{l}0 \\
\stackrel{0}{0} \\
\stackrel{0}{0}\end{array}$ \\
\hline & 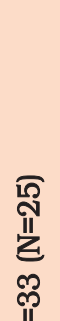 & 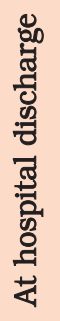 & 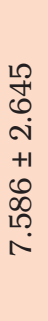 & 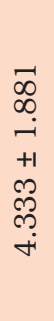 & 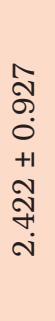 & 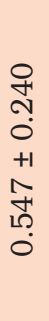 & 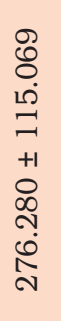 & 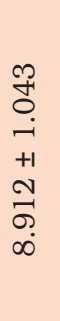 & 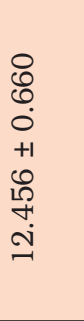 & $\begin{array}{l}\infty \\
\varpi \\
0 \\
0 \\
+1 \\
0 \\
0 \\
\sigma \\
-\end{array}$ & 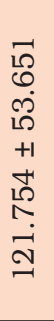 & 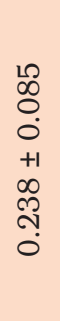 \\
\hline छ్ల & & 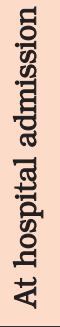 & 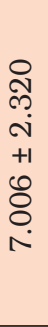 & 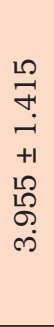 & 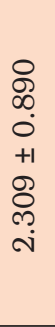 & 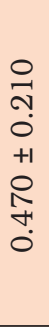 & 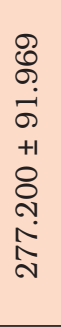 & $\begin{array}{l}0 \\
\varnothing \\
0 \\
-i \\
+1 \\
\circ \\
\infty \\
\infty \\
\infty \\
\infty\end{array}$ & 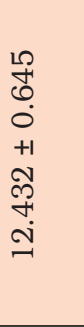 & $\begin{array}{l}\overrightarrow{0} \\
\stackrel{0}{0} \\
0 \\
+1 \\
\vec{N} \\
\infty \\
-1\end{array}$ & 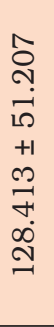 & \begin{tabular}{l}
0 \\
0 \\
0 \\
0 \\
+1 \\
0 \\
\multirow{2}{*}{} \\
0
\end{tabular} \\
\hline 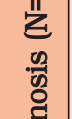 & & 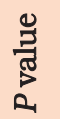 & $\begin{array}{l}\text { Nิ } \\
\text { ஸे }\end{array}$ & ஓ & 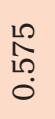 & 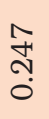 & $\begin{array}{l}\stackrel{8}{\circ} \\
\text { ! } \\
0\end{array}$ & $\begin{array}{l}\overrightarrow{0} \\
\stackrel{0}{0}\end{array}$ & 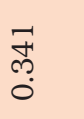 & $\begin{array}{l}\text { ம) } \\
\text { † } \\
\stackrel{0}{0}\end{array}$ & $\begin{array}{l}\text { 尺े } \\
\text { ֻุ } \\
0\end{array}$ & 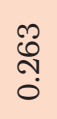 \\
\hline 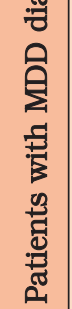 & 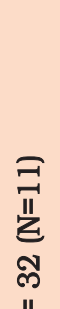 & 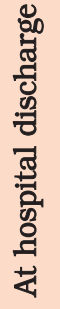 & 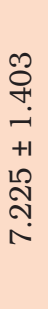 & 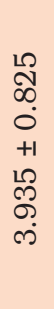 & 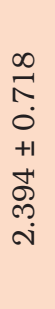 & 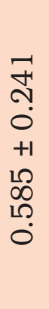 & 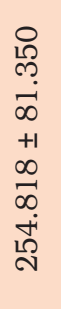 & 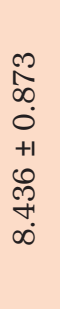 & 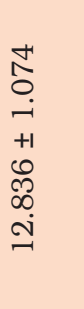 & 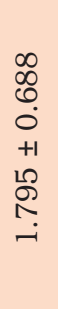 & 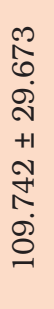 & 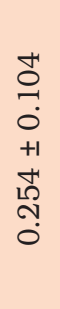 \\
\hline & & 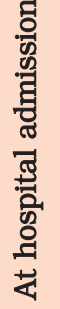 & 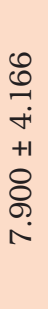 & 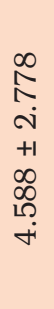 & 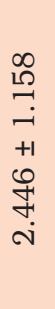 & 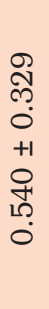 & 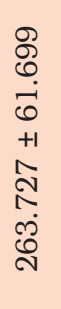 & $\begin{array}{l}\infty \\
\stackrel{1}{1} \\
0 \\
+1 \\
+1 \\
\infty \\
1 \\
\infty \\
\infty\end{array}$ & 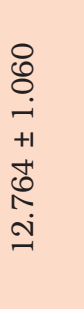 & 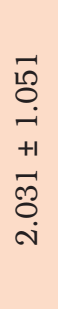 & 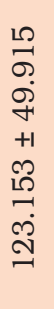 & $\begin{array}{l}10 \\
\infty \\
0 \\
0 \\
+1 \\
+1 \\
\stackrel{2}{0} \\
\text { N. } \\
0\end{array}$ \\
\hline & & 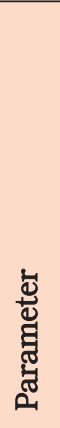 & 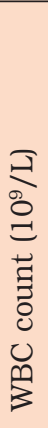 & 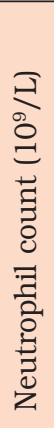 & 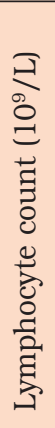 & 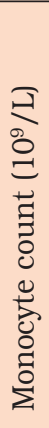 & 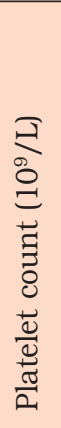 & 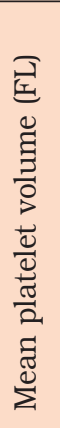 & 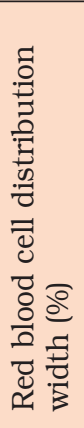 & 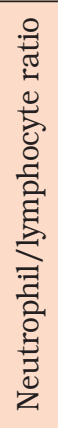 & 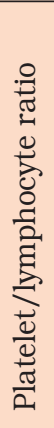 & 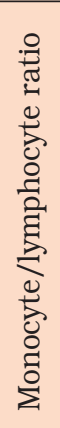 \\
\hline
\end{tabular}


days on average) and the patients were administered one of the following antidepressant medication in a recommended dosage regimen - duloxetine, escitalopram, moclobemide, venlafaxine, vortioxetine - during their hospitalization. The collected samples were analysed using Mindray BC-5500 Hematology Analyzer (Mindray, China) and the obtained hemogram data were evaluated. The list of analysed parameters is in the tables 1, 2, and 3.

Statistical analyses were performed through MYSTAT (SYSTAT, USA). The test of normality was performed and, accordingly, single t-test or Mann-Whitney U-test were used for the data assessment. A p-value $<0.05$ was considered as statistically significant.

\section{RESULTS}

There were no significant differences between males and females in any of the observed parameters. The values of white blood cell count, neutrophil count, lymphocyte count, monocyte count, platelet count, mean platelet volume, red blood cell distribution width, and all monitored ratios - NLR, PLR, and MLR at the hospital admission and at the day of discharge are listed in the Table 1 . Monocyte count was the only parameter that significantly changed during the hospitalization $(0.491 \pm 0.250$ at the beginning of antidepressant treatment $v$ s $0.559 \pm 0.237$ at the end of the stay in the hospital; $p=0.007$ ).

The same tendency with increased value of monocyte count at the end of the hospital stay was recorded in the group of patients treated with Serotonine-Norepinephrine Reuptake Inhibitor (SNRI) antidepressant venlafaxine $(\mathrm{N}=23 ; 0.467 \pm 0.226$ at admission, vs $0.553 \pm 0.271$ at the end of hospital stay; $p=0.008)$. Furthermore, in the group of patients treated with venlafaxine we observed another significantly changed parameter MLR ratio (increase from $0.200 \pm 0.072$ at admission to $0.240 \pm 0.095$ at discharge; $\mathrm{p}=0.011$; Table 2).

\section{DISCUSSION}

In our study selected blood cell counts were measured and, subsequently, blood cell ratios in patients admitted to hospital with a diagnosis of major depressive disorder were calculated. The blood samples were collected at admission and on discharge day. On average, all blood cell parameters were within the normal range as in healthy population. The major finding of this retrospective study was that the monocyte count significantly increased after the hospital stay and proper antidepressant therapy. In patients treated with venlafaxine there was a significant increase also in MLR after hospitalization. The elevated levels of monocytes in mental disorders such as depression, bipolar disease, and schizophrenia have been already revealed. The attention is turned to microglia mediated chronic activation of immune system in the brain. Microglia, macrophages acting as immune defence in the central nervous system, play a vital role in pathological synaptic pruning and altered neuroplasticity $(4,17,22,23)$.

Several studies have shown that the number of white blood cell and neutrophils and the level of C-reactive protein increase in MDD and can escalate the symptoms of depression $(3,24)$. On the other hand, probably due to inflammatory or chronic stress-induced cellular immunosuppression, the lymphocyte concentrations decrease. Thus, it results in a higher NLR parameter $(5,15)$. While neutrophils represent the first line of immune defence, lymphocytes are considered as specific inflammatory mediators. The combination of these immune cells enables to calculate so called NLR parameter, more predictive and less affected by confounding factors than either of them alone $(15,25)$. However, we did not identify any significant change in NLR parameter, nor in PLR, MPV, and RDW parameters after hospitalization. 
In our study we did not evaluate red blood cell, haemoglobin, and haematocrit counts as those parameters are on one hand gender specific and, moreover, there has not been reached any consensus whether they play any role in MDD or not. Nonetheless, there have been published a few studies with a convincing correlation. Some authors found that those parameters were lower in MDD patients comparing to control group. They explained it either as an inhibition of erythropoiesis due to systemic inflammation or as a result of long-term poor appetite which causes haemoglobin level decrease $(3,26)$. A longitudinal study found out that a low baseline level of haemoglobin in older men predicted incident depression (27). Another study revealed that a significant association existed between depression and anaemia and that anaemia prevalence increased with depression severity (28).

Many studies have excluded a whole group of subjects due to the chronic conditions they suffered from. The exclusion criteria were, for instance, having an autoimmune disease, any infection, severe systemic diseases, epilepsy, diabetes mellitus, hypertension, other cardiovascular disease, liver or kidney diseases. However, it has been found that in the conditions with an activated peripheral immune system the production of pro-inflammatory cytokines can lead to an exacerbation of sickness and the development of depressive symptoms in vulnerable subjects (5). Moreover, inflammatory cytokines can cause changes in the central nervous system neurotransmitters and in synaptic plasticity $(3,29,30,31)$. As depression is now a well-known comorbidity for various chronic illnesses and vice versa $(3,5,10,29$, 31,32 ), these exclusions limit the findings and do not necessarily characterise a real population.

In our study we had four patients with diabetes mellitus and one patient with a history of heart attack and present coronary artery disease diagnosis. None of the patients took any glucocorticoid therapy, so the level of monocytes in blood could not be influenced that way. The actual pharmacotherapy of depression was changed in almost half of the patients with recurrent major depressive disorder after admission to hospital - mainly from SSRI group (selective serotonin reuptake inhibitors) to serotonin-norepinephrine reuptake inhibitor (SNRI) venlafaxine.

We are aware of limitations of this study, including the small sample size, short period for observing significant changes in blood parameters, and no control group. Another limitation might be previous antidepressant pharmacotherapy that was changed in half cases of patients at admission. No strict exclusion criteria are on one side a limitation, but on the other side it might be of benefit that the sample better represents the real situation in population.

\section{CONCLUSIONS}

The pharmacotherapy and additive treatment of the patients with MDD led only to mild changes in blood cells counts, predominantly related to monocytes count and monocyte/lymphocyte ratio. A further research is necessary to confirm the relationship between non-specific blood cell markers and major depressive disorder. Particularly interesting might be a study containing blood cell counts, blood cell ratios, pro-inflammatory cytokines, and metabolomics analysis of a patient with major depressive disorder at the same time.

Acknowledgements: The study was supported by grants VEGA 1/0255/18, VEGA 1/0044/18, and by the project "Biomedical Center Martin" (ITMS code: 26220220187) - the project is cofinanced from EU sources. 


\section{REFERENCES}

1. Available at: http://apps.who.int/iris/bitstream/handle/10665/254610/WHO-MSD-MER-2017. 2-eng. Accessed September 18, 2018.

2. Available at: http://www.who.int/mental_health/advocacy/en/Call_for_Action_MoH_Intro. Accessed September 18, 2018.

3. Cai L, Xu L, Wei L, Chen W. Relationship of Mean Platelet Volume To MDD: A Retrospective Study. Shanghai Arch Psychiatry. 2017;29(1):21-29.

4. Rosenblat JD, Cha DS, Mansur RB, Mcintyre RS. Inflamed moods: a review of the interactions between inflammation and mood disorders. Prog Neuropsychopharmacol Biol Psychiatry. 2014;53:23-34.

5. Dantzer R, O'connor JC, Freund GG, Johnson RW, Kelley KW. From inflammation to sickness and depression: when the immune system subjugates the brain. Nat Rev Neurosci. 2008;9(1):46-56.

6. Krishnadas R, Cavanagh J. Depression: an inflammatory illness? J Neurol Neurosurg Psychiatry. 2012;83(5):495-502.

7. Leighton SP, Nerurkar L, Krishnadas R, Johnman C, Graham GJ, Cavanagh J. Chemokines in depression in health and in inflammatory illness: a systematic review and meta-analysis. Mol Psychiatry. 2018;23(1):48-58.

8. Hurley LL, Tizabi Y. Neuroinflammation, neurodegeneration, and depression. Neurotox Res. 2013; 23(2):131-44.

9. Maes M. Depression is an inflammatory disease, but cell-mediated immune activation is the key component of depression. Prog Neuropsychopharmacol Biol Psychiatry. 2011;35(3):664-75.

10. Janssen DG, Caniato RN, Verster JC, Baune BT. A psychoneuroimmunological review on cytokines involved in antidepressant treatment response. Hum Psychopharmacol. 2010;25(3):201-15.

11. Furtado M, Katzman MA. Examining the role of neuroinflammation in major depression. Psychiatry Res. 2015;229(1-2):27-36.

12. Valkanova V, Ebmeier KP, Allan CL. CRP, IL-6 and depression: a systematic review and meta-analysis of longitudinal studies. J Affect Disord. 2013;150(3):736-44.

13. Garcia-Rizo C, Fernandez-Egea E, Miller BJ, et al. Abnormal glucose tolerance, white blood cell count, and telomere length in newly diagnosed, antidepressant-naïve patients with depression. Brain Behav Immun. 2013;28:49-53.

14. Demir S, Atli A, Bulut M, et al. Neutrophil-lymphocyte ratio in patients with major depressive disorder undergoing no pharmacological therapy. Neuropsychiatr Dis Treat. 2015;11:2253-8.

15. Demircan F, Gözel N, Kılınç F, Ulu R, Atmaca M. The Impact of Red Blood Cell Distribution Width and Neutrophil/Lymphocyte Ratio on the Diagnosis of Major Depressive Disorder. Neurol Ther. 2016;5(1):27-33.

16. Balta S, Demirkol S, Kucuk U. The platelet lymphocyte ratio may be useful inflammatory indicator in clinical practice. Hemodial Int. 2013;17(4):668-9.

17. Mazza MG, Lucchi S, Tringali AGM, Rossetti A, Botti ER, Clerici M. Neutrophil/lymphocyte ratio and platelet/lymphocyte ratio in mood disorders: A meta-analysis. Prog Neuropsychopharmacol Biol Psychiatry. 2018;84(Pt A):229-236.

18. Aydin sunbul E, Sunbul M, Yanartas O, et al. Increased Neutrophil/Lymphocyte Ratio in Patients with Depression is Correlated with the Severity of Depression and Cardiovascular Risk Factors. Psychiatry Investig. 2016;13(1):121-6.

19. Jackson SR, Carter JM. Platelet volume: laboratory measurement and clinical application. Blood Rev. 1993;7(2):104-13.

20. Threatte GA. Usefulness of the mean platelet volume. Clin Lab Med. 1993;13(4):937-50.

21. Adhikari A, Dikshit R, Karia S, Sonavane S, Shah N, De sousa A. Neutrophil-lymphocyte Ratio and C-reactive Protein Level in Patients with Major Depressive Disorder Before and After Pharmacotherapy. East Asian Arch Psychiatry. 2018;28(2):53-58.

22. Beumer W, Gibney SM, Drexhage RC, et al. The immune theory of psychiatric diseases: a key role for activated microglia and circulating monocytes. J Leukoc Biol. 2012;92(5):959-75. 
23. Yirmiya R, Rimmerman N, Reshef R. Depression as a microglial disease. Trends Neurosci. 2015;38(10):637-658.

24. Zorrilla EP, Luborsky L, Mckay JR, et al. The relationship of depression and stressors to immunological assays: a meta-analytic review. Brain Behav Immun. 2001;15(3):199-226.

25. Azab B, Camacho-Rivera M, Taioli E. Average values and racial differences of neutrophil lymphocyte ratio among a nationally representative sample of United States subjects. PLoS ONE. 2014;9(11):e112361.

26. Wang Y, Huang F. N-3 Polyunsaturated Fatty Acids and Inflammation in Obesity: Local Effect and Systemic Benefit. Biomed Res Int. 2015;2015:581469.

27. Trevisan C, Veronese N, Bolzetta F, et al. Low Hemoglobin Levels and Risk of Developing Depression in the Elderly: Results From the Prospective PRO.V.A. Study. J Clin Psychiatry. 2016;77(12):e1549-e1556.

28. Vulser H, Wiernik E, Hoertel N, et al. Association between depression and anemia in otherwise healthy adults. Acta Psychiatr Scand. 2016;134(2):150-60.

29. Najjar S, Pearlman DM, Alper K, Najjar A, Devinsky O. Neuroinflammation and psychiatric illness. J Neuroinflammation. 2013;10:43.

30. Tremblay MĖ, Majewska AK. A role for microglia in synaptic plasticity? Commun Integr Biol. 2011;4(2):220-2.

31. Mcnally L, Bhagwagar Z, Hannestad J. Inflammation, glutamate, and glia in depression: a literature review. CNS Spectr. 2008;13(6):501-10.

32. Laske C, Zank M, Klein R, et al. Autoantibody reactivity in serum of patients with major depression, schizophrenia and healthy controls. Psychiatry Res. 2008;158(1):83-6.

Received: October, 18, 2018

Accepted: December, 26, 2018 